\title{
Perspectives on endogenous and exogenous tissue engineering following injury to tissues of the knee
}

\author{
David A. Hart ${ }^{1,2}$ \\ ${ }^{1}$ McCaig Institute for Bone \& Joint Health University of Calgary, Calgary, Canada \\ ${ }^{2}$ The Centre for Hip Health \& Mobility, Department of Family Practice, University of British Columbia, Vancouver, Canada \\ Email: hartd@ucalgary.ca
}

Received 29 October 2013; revised 14 December 2013; accepted 21 December 2013

Copyright (C) 2014 David A. Hart. This is an open access article distributed under the Creative Commons Attribution License, which permits unrestricted use, distribution, and reproduction in any medium, provided the original work is properly cited. In accordance of the Creative Commons Attribution License all Copyrights (C) 2014 are reserved for SCIRP and the owner of the intellectual property David A. Hart. All Copyright (C 2014 are guarded by law and by SCIRP as a guardian.

\section{ABSTRACT}

The knee is a multi-component organ system comprised of several tissues which function coordinately to provide mobility. Injury to any one component compromises the integrity of the system and leads to adaptation of the other components. Over time, such events often lead to dysfunction and degeneration of the knee. Therefore, there has been considerable research emphasis to repair injured components in the knee including cartilage, menisci, and ligaments. Approaches to improving healing and repair/regeneration of knee tissues have included surgery, anti-sense gene therapy, injection of growth factors and inflammatory cytokine antagonists, transplantation of in vitro expanded chondrocytes, enhancement of endogenous cells via microfracture, injection of mesenchymal stem cells, and implantation of in vitro tissue engineered constructs. Some of these approaches have led to temporary improvement in knee functioning, while others offer the potential to restore function and tissue integrity for longer periods of time. This article will review the status of many of these approaches, and provide a perspective on their limitations and potential to contribute to restoration of knee function across the lifespan.

\section{KEYWORDS}

The Knee as an Organ; Tissue Engineering; Mesenchymal Stem Cells; Joint Injury Repair

\section{INTRODUCTION}

The knee is a complex "organ system" which is comprised of several tissues (e.g. intra- and extra-articular ligaments, tendons, muscle, cartilage, menisci, capsule, and synovium) which arises during development to function as an integrated unit during mobility [1-3]. All of the tissues of the knee are vascularized and innervated to variable extents except the articular cartilage which is devoid of vascularity and innervation, likely in part due to its requirement to function in a very intensive biomechanical loading environment.

Following development during fetal life, the tissues of the knee are required to proceed through post-natal life with maturation, puberty and finally skeletal maturity steps, while maintaining their coordinate functioning [1]. Once in skeletal maturity, the knee maintains its integrity via biomechanical stimulation $[1,4]$ and biological factors, including systemic nutrients, growth regulators and hormones, as well as others.

The major responsibility to adequately maintain the integrity of the extracellular matrix matrix (ECM) in the various tissues of the knee, which is critical for the functioning of the knee falls to a variety of cells that populate the tissues. Each tissue is populated by a variety of cell types uniquely differentiated to both survive in specific biomechanical environments, and to provide contributions to load-dependent tissue homeostasis [4]. Thus, articular hyaline cartilage has cells that are unique to different layers (superficial zone, central zone and deep zone) [discussed in 5,6], and menisci have cells in different parts of the tissue which exhibit different appearances [7], likely in part due to different mechanical environments and association with different tissue molecules (Stephen Andrews, Ph.D. Thesis, University of Calgary, 2013). Furthermore, even in ligaments associated with the knee (e.g. the intra-articular ACL, the extra-articular MCL), the cells are reported to be different $[8,9]$ and it is known that the two ligaments operate in two different loading environments (e.g. the ACL in relatively high loading conditions versus the MCL which operates in a normally low load 
environment) [10]. Therefore, not only is the ECM in different knee tissues different, the cells in the different tissues are heterogeneous. Both conditions pose challenges to approaches to regenerating injured tissues to restore integrated functioning of the knee.

Not only do cells in the tissues respond in a positive manner to biomechanical stimulation by increased expression of anabolic genes (e.g. growth factors, ECM components), but also they respond to a lack of mechanical stimulation/immobilization [discussed in 1,4,11]. That is, tissues of the knee subscribe to the "Use it or lose it" paradigm. If the tissues experience a decline or loss of biomechanical stimulation, they induce a set of catabolic genes that contribute to atrophy of the tissue down to a new homeostatic "set point" (e.g. the point at which a balance between anabolism and catabolism is reestablished for the new mechanical demands) where this catabolic subset of genes is again repressed [11]. In vivo, immobilization of the skeletally immature rabbit knee leads to a failure to growth even when tissues in the contralateral knee continue to grow [discussed in 1,4]. One possibility to explain how the immobilized tissues fail to grow and mature in the face of systematic growth regulators is that biomechanical stimulation leads to expression of functionally active cell receptors for such mediators, and this essential component of the cells is compromised when the tissues are deprived of stimulation/ loading $[1,10]$.

Such findings have implications for both approaches to enhancing repair/regeneration using enhancement of endogenous cell function and associated mechanisms, as well as exogenous approaches to tissueing engineering of tissue replacements. An example of the latter is the work of Goulet and co-workers who have shown that biomechanical loading of a tissue engineered ACL replacement leads to a stronger more functional engineered tissue when transplanted in vivo into goats or dogs [reviewed in 12].

\subsection{Enhancement of Tissue Engineering via Alteration of Endogenous Cells}

In most tissues of the knee (the aneural, avascular articular cartilage is a notable exception), the cells of either the injured tissue, or puripotent/multipotent (e.g. mesenchymal stem cells [MSC] or mesenchymal progenitor cells [MPC]) cells associated with the synovial fluid or synovial membrane of the intra-articular environment are available for assisting in the healing process [discussed in 13-15].

Following injury to one or more tissues of the knee, or development of a degenerative condition (e.g. idiopathic with no known overt injury) such as osteoarthritis, leads to a loss of joint integrity. Injury to some tissues, such as the extra-articular MCL, leads to the functional healing, but slow remodeling of the tissue in preclinical models [reviewed in 16]. For the MCL, a complete transection or rupture of the tissue in most instances does not require surgical intervention and the healing proceeds normally. The initial phases of wound healing (inflammation, matrix deposition, and slow remodeling) take place but the matrix deposited is not normal and is a scar-like tissue. While the cellularity of the healing MCL gradually returns to normal levels, the biomechanical integrity of the healed MCL is somewhat compromised up to 2 years later [17]. Part of this is likely due to the slow crosslinking of the collagen matrix, while another part is likely due to the slow re-appearance of larger collagen fibrils in the scar tissue [discussed in 18,19]. What likely allows the repaired MCL to be sufficiently operational to regain its role as a knee stabilizer is that it is extra-articular, and operates as a low-load stabilizer [discussed in 10].

Use of in vitro expanded autologous and allogenic chondrocytes and meniscal cells, and subsequent implantation in vivo have been extensively studied over the past decade or more [reviewed in 20-25]. While somewhat expensive, this approach of expanding endogenous cells has proven to be successful for a number of patients, particularly younger patients with limited defects in their articular cartilage of the knee. However, removal of autologous cartilage from non-weight bearing areas of the knee cartilage to obtain chondroctyes does induce some damage to the remaining cartilage in the knee, and there are some concerns regarding dedifferentiation of chondrocytes in vitro during expansion. In spite of limitations, this approach appears to have fairly long term clinical efficacy, particularly for a subset of patients.

Attempts to enhance endogenous repair (which is not regeneration) via approaches such as treatment of early scar tissue with anti-sense reagents to specific molecular targets were only partially successful, but certainly proved the concept was potentially viable [26,27]. In a rabbit model, the injured MCL was injected with either an antisense reagent directed towards the small leucine-rich proteoglycan (SLRP) decorin, a sense reagent, or vehicle early after injury. Subsequent sacrifice and analysis revealed that the anti-sense treated MCL was biomechanically stronger than the others, and that significantly larger numbers of collagen fibrils were detected in the antisense treated animals [26]. As decorin is known to bind to collagen and play a role in collagen assembly [discussed in 26,27], this outcome was hypothesized to occur. However, over time, the anti-sense treated scar tissue reverted to a more scar-like material with mainly small collagen fibrils (unpublished). Thus, it would appear that even with an impact early after injury, the healing process reverted to the normal sequence of progression with time. Therefore, while such interventions can enhance the healing process in the short term, they are apparently 
ineffective in permanently shifting the outcomes. The basis for this scenario is unknown, but it could relate to the short half-life of the reagents, or the overpowering influence of the mediator milieu in the otherwise healthy rabbit with an injured MCL [discussed in 28,29].

A second approach to enhance the activity of endogenous cells is via the use of reagents such as Platelet-Rich Plasma (PRP) [reviewed in 30-34]. As normal platelets contain a number of mediators, including growth factors and other biologically active molecules, injection of such preparations could result in the release of several "repair-enhancing" molecules or molecules which may negate the impact of endogenous mediators which are exerting a negative or counter-productive influence on repair. Since such preparations can be used in an autologous manner, this is a significant advantage. However, being autologous can also be a disadvantage if an individual has compromised platelets or plasma.

While the rationale for using such platelet preparations is attractive, the literature would indicate that responses to injection of such preparations is quite variable (see reviews indicated above), and there are not a large number of appropriately controlled clinical trials. Additionally, the outcome measures used by different investigators in various studies can differ, and range from those focused on actual repair to symptomatic relief (most notably pain). As platelets, and their contents, can be influenced by a number of factors, it is not surprising that outcomes may also be variable. Furthermore, the disease setting (early, late; concurrent use of medications, etc.) also can impact effectiveness. Thus, for PRP, the "jury" is still out regarding effectiveness and the mechanisms by which it is effective in some individuals, and whether it is more effective in acute (e.g. torn menisci, tendons, ligaments) versus chronic conditions (e.g. tendinosis, osteoarthritis with cartilage degeneration). Likewise, when PRP is "successful" it is not known whether it is influencing endogenous fibroblasts, chondrocytes, fibrochondrocytes, or is actually working at the level of mesenchymal stem/ progenitor cells in the damaged tissues, or derived from a nearby source such as the synovial fluid or synovial membrane.

It is clear that preparations such as PRP contain multiple growth factors and other mediators, and the effectiveness is variable. At the opposite end of that scale, a number of studies have attempted to enhance repair of specific joint tissues, or restore joint function via use of individual growth factors, or reagents known to influence the activity of molecules within the abnormal joint. For the most part, such studies with growth factors known to be involved in repair have not exerted a highly significant impact on acute repair in normal healthy individuals/preclinical models [e.g. 35]. However, a study from Salo's group [36] has indicated that timely use of nerve growth factor (NGF) can positively enhance repair of injured ligaments. Whether this influence on repair is due to an impact of the growth factor on the re-innervation of damaged tissues [reviewed in 37], or some other nonneural effects of NGF, remains to be determined.

Other researchers have taken a somewhat different tack to interfere with abnormal processes either within an injured joint or fibrotic processes in general. An example is studies which showed that treatment of mice knees with anti-TGF-beta antibodies inhibited osteophyte formation in mouse knees with osteoarthritis [38]. Similarly, use of decorin (which binds TGF-beta) was also shown to inhibit renal and pulmonary fibrosis due to excess levels of this growth factor $[39,40]$. Thus, by effectively removing a known stimulus which was present, one could modulate cell responses leading to abnormal outcomes.

An additional approach to enhance restoration of function by endogenous cells has been developed by orthopedic surgeons in an attempt to restore cartilage loss. This procedure involves micro fracturing of the bone that was exposed by articular cartilage loss to induce blood, bone marrow elements, and likely stem cells associated with the subchondral bone to localize and form a fibrocartilage-like surface in the compromised area [reviewed in 41-43]. As the fibrocartilage formed by such a procedure is not as resilient as the hyaline cartilage that was there initially, this procedure is likely temporary although some patients experience prolonged benefit [43].

In summary, attempts to enhance functional and structural repair by stimulating endogenous cells in the damaged tissues or the processes known to stimulate wound healing have met with mixed results. The findings have been very dependent on variability in individual responses, or effects have been dependent on local environments. This latter point is likely very relevant to some of the discussion which follows related to applications of stem/ progenitor populations for cellular repair, as well as tissue engineered tissue replacements.

\subsection{Use of Stem/Progenitor Cells to Repair the Knee: Tissue Engineering of Replacement Tissues or Injection of Cells?}

It is clear from the literature that many tissues contain cells which have some properties consistent with them being either mesenchymal stem or progenitor cells. In addition, such cells can be readily found/detected in bone marrow (BM), adipose tissue (peripheral fat obtained by liposuction or fat pads within the knee) [reviewed in 44], skin, synovial membranes (SM), as well as synovial fluid (SF) [45,46; and many others]. While such cells appear to be able to differentiate into different lineages (e.g. bone, cartilage, adipocytes, fibroblasts), cells obtained from BM appear to preferentially become bone-related, while those of SM and SF appear to be oriented towards 
chondrogenesis $[47,48]$. Such variation, plus ease of obtaining the cells, can influence the approaches taken to address either approach: in vitro tissue engineering versus injection of cells into the knee and hope they home to the damaged area and initiate repair. These two approaches are intrinsically different, but have to meet some common challenges when one considers joint restoration from a structural and biomechanical perspective versus injection of cells which need to home to the damaged tissue and initiate repair, often times in the absence of a suitable scaffold such as in advanced osteoarthritis with cartilage loss and/or tears and degeneration of the menisci.

\subsection{Use of Mesenchymal Stem/Progenitor Cells to Repair the Injured Knee}

As discussed above, mesenchymal stem/progenitor cells (MSC/P cells) have been isolated repeatedly from a number of tissues/sources that would permit autologous use. In addition, cells with such characteristics have also been isolated from placenta and related tissues $[49,50]$ which could possibly be used in an allogeneic setting. While many of the studies employing isolated cells have used preclinical models to characterize effectiveness, others have used such cells in patients with osteoarthritis and other knee conditions. Unfortunately, in some of the latter situations, their use has been empirical and not supported by adequately controlled clinical trials [discussed in 22,51; and many others]. However, this has been changing and for just adipose-derived cells, over 40 clinical trials have been registered with the NIH (USA) by 2012 [discussed in 44]. Furthermore, in many cases, the outcomes are related to symptom (e.g. pain) management rather than tissue repair and structural restoration, but likely this will also change going forward as more clinical trials come to fruition. Therefore, in the coming few years, evidence for the efficacy of MSC from various sources will be available and informed decisions on their use will be possible.

One of the key findings to date is that only a small percentage of the MSC populations injected into a joint actually remain in the joint or at the site of the injury. For instance, it was shown that very few labeled injected cells associated with induced defects in knee menisci [52; and many others]. This is a common finding, that following injection of literally millions of cells, only a small percentage of cells remain at the site of injury over time. There are likely several explanations for this finding. Firstly, populations of cells with the phenotype of MSC are quite heterogeneous, even from a location such as synovial fluid, with respect to proliferation and differentiation potential [48; Kutcher et al., in preparation; J. Kutcher, MSc Thesis, University of Calgary, 2012]. Isolating cloned cells by limiting dilution analysis of synovial fluid MSC has revealed significant heterogeneity in the characteristics of such cells. Thus, perhaps only a small percentage of what are called MSC from a particular source, are likely actually able to home to a site of injury and contribute to repair of the injury either directly, or indirectly via secretion of essential growth mediators or molecules facilitating repair (e.g. "nurse cells"). The observations after injection of MSC into knees are not unique to this environment, and this outcome has also been observed in models of heart damage and other tissue injuries.

A second potential complicating factor associated with injecting "normal” MSC into injured or damaged knees is that the inflammatory environment resulting from the injury is inhospitable for the proper functioning of the injected MSC. MSC isolated from the synovial fluid or synovial membranes of sheep knees that had incurred an injury led to lower ability of the cell population to differentiate towards the chondrocyte phenotype [47]. Interestingly addition of IL-1 to populations of MSC from normal sheep knees led to a decline in ability to differentiate towards the same lineage. Furthermore, this decline was $~ 30 \%$ - $40 \%$ and it reached a plateau with increasing concentrations of IL-1. Thus, only a subset of MSC in the population was responsive to IL-1.

Analogous studies with human knee MSC derived from SF of normal knees, and knees from individuals with osteoarthritis (OA) have provided further support for the concept that inflammation in a knee arising from either an injury or a disease such as OA can lead to modifications in the effectiveness of the cells. Firstly, MSC from OA patients apparently have lost their ability to selfaggregate and differentiate towards a chondrogenic phenotype [15]. However, if the cells are aggregated artificially by pelleting, they retain the ability to differentiate. Loss of this feature of self-aggregating would likely impact the ability of the cells to home to a site of damage, aggregate, and assist in the repair of the injury. Analysis of SF from OA patients for the presence of inflammatory mediators using a multiplexing approach has indicated that the SF does indeed contain mediators that are either not present in SF from normal knees, or the levels are greatly increased [53]. Interestingly, addition of one of those mediators identified in OA SF, specifically MCP-1, to MSC from normal knees led to a loss of the self-aggregating characteristic [54]. Therefore, injecting MSC into an inhospitable environment may compromise their ability to initiate repair and home to a site in need of repair. This interpretation may also explain why the endogenous MSC in an inflamed and injured knee are ineffectual in inducing repair.

Based on the above discussion, it may be critical to minimize the inflammation in the joint prior to injecting MSC to facilitate repair. This is likely true for both treatment of early OA, or alternatively, repair of knees sub- 
jected to inflammatory arthritis such as rheumatoid arthritis [55]. In addition, it may be necessary to utilize MSC from a different tissue source (e.g. Bone Marrow) for injection since MSC from inflamed knees appear to maintain the altered phenotype for several passages in vitro [47; Ando et al., unpublished]. Thus, this approach using MSCs has potential, but improvements in their homing to specific locations and abilities to facilitate repair are still needed [reviewed in 51].

Finally, injecting MSC from a variety of tissue sources has also been attempted where the outcomes are not related primarily to structural repair of the tissues (although some structural improvement has been noted in some patients), but instead, the alleviation of symptoms (e.g. primarily pain such as in OA). This is not unreasonable as stem cells from some sources have immunomodulatory properties [56,57; and many others]. Thus, injecting MSC into knees with advanced OA does not offer much hope to completely repair the extensive damage to the articular cartilage, menisci, and other involved tissues, but if the MSC were indeed a supply of anti-inflammatory molecules, or molecules that may influence neural activities contributing to the pain of OA, then they may have value alone or in conjunction with pharmaceuticals. As an example, injection of MSC (such as obtained by liposuction or bone marrow aspiration) has been reported to alleviate pain in some patients [58-60; and many others]. They may not be effective in this regard in all patients, but certainly many patients report receiving benefit. Whether some of such benefit is related to the effectiveness of the cells, or is due to a "placebo" effect is not clear, and one has to consider the placebo effect as a factor with respect to symptoms such as pain which can be subjective. This point stresses the need for well controlled clinical trials in this area to tease out where the benefits are and to perhaps identify patient subsets that would benefit more than others from injections of such cells (e.g. precision or personalized medicine).

\subsection{Use of Mesenchymal Stem/Progenitor Cells for Tissue Engineering Replacement Tissues for Injured/Damaged Knees}

From the above discussion regarding cells, it is very challenging to repair an extensively injured or damaged knee with multiple tissues involved and with respect to articular cartilage, complete loss of tissue resulting in bone-on-bone and very little residual scaffold to use as a template. Therefore, likely the best application for in vitro tissue engineering of tissue replacements will be for limited size defects in the articular cartilage or menisci, or for a tissue of defined specifications [e.g. an ACL replacement; 61].

For the latter, many studies have used fibroblasts rather than MSC [discussed in 62; and reviewed in 12,
63]. However, such in vitro engineered constructs (boneligament-bone configurations) have been implanted into goats and they have survived and functioned. Whether these avascular, aneural constructs gradually become more "scar-like" over time as host cells infiltrate the implanted engineered construct remains to be confirmed. A key aspect of generating such engineered constructs of fibroblasts + a scaffold is the application of mechanical loading during the generation of the construct. Such loading appears to lead to a much stronger and organized construct which then has a much better chance for survival once implanted as a "reconstructed" ACL even if it is a single band of ligament-like collagen-based material. In the future, it is likely that the use of MSC for the generation of ACL replacements will become the norm, perhaps using SF MSC since they would be in the intraarticular environment of the ACL to start with and thus, perhaps be positioned to participate in endogeneous repair already.

In a number of studies resulting from investigations from the Nakamura laboratory at Osaka University, and in collaboration with the author, Tissue Engineered Constructs (TEC) for cartilage, meniscal and bone repair have been generated from MSC derived from synovial membranes or synovial fluid [64-68]. The model of choice for these studies has been pigs, a species with a physiology similar to humans, and a large animal with knees also similar to humans, but similar TEC can be generated from human MSC [69]. In vitro generated allogeneic TEC have been implanted into defined defects in articular cartilage of juvenile and skeletally mature pigs and survived very well out to one year post-implantation (the last time point assessed) and integrated well with the adjacent cartilage $[64,68]$. Similarly, such TEC have been implanted into meniscal defects in the knee and also survived very well after implantation [67]. Interestingly, the TEC implanted into cartilage defects were not differentiated in vitro, and therefore, differentiated in vivo after implantation under the in vivo mechanical and biological environment to become Collagen II rich and histologically appear to be cartilage-like. While a very good approximation of normal articular cartilage, the implants were not perfect as their most superficial surface layer (e.g. lamina splenden) did not have all of the characteristics of normal cartilage [65]. Whether such TEC implanted into cartilage defects will survive and provide function over the lifetime of the animal remains to be seen, although it is a quite promising approach based on current findings. This approach may have clinical application in patients with limited size defects in the cartilage or menisci, particularly younger physically active individuals.

While the above TEC approach is promising for repair of damaged/injured cartilage and menisci (and poten- 
tially tendons and ligaments as well), the implanted TEC would still have to overcome the challenges related to the inflammatory environment associated with the initial injury or the process of further degeneration following the injury (discussed above). In the pig model studies, such influences did not appear to be critical to the survival of the TEC, but it certainly could be a factor in possibly older patients, or those with more extensive damage where endogenous cells were being recruited to augment the functionality of the implant.

\section{SUMMARY}

A number of cellular and tissue engineering approaches have been investigated to facilitate repair of damaged/ injured tissues in the knee. Some of these, such as in vitro tissue engineering for repair of cartilage and menisci are quite promising based on current findings. Other approaches using MSC may be effective in modifying symptoms associated with knee injuries or degenerative disease processes in the knee, but the possibility that such approaches will lead to structural repair, particularly in the absence of an appropriate scaffold, is not great in the current understanding of how the joint functions. One possibility to enhance the functioning of autologous MSC to facilitate repair may be to generate an acellular scaffold via tissue printing of appropriate dimensions (derived from imaging modalities), and possibly containing growth factors or homing molecules, which could be implanted and then autologous MSC injected to populate the implanted template. Thus, the appropriate template scaffold could be generated separate from the cells, and then repopulated with undifferentiated or in vitro differentiated MSC. The undifferentiated cells could then differentiate under more in vivo conditions.

Due to the complexity of the in vivo environment and the processes involved in tissue repair, it is not likely that anti-sense or limited target specificity approaches will have much benefit to repair the tissues of the knee. However, a combination of tissue engineering approaches + MSC, and with the control of the inflammatory environment within the knee may offer the best hope for the future of knee repair with a return to optimal functioning of this organ system $[1,16]$.

\section{ACKNOWLEDGEMENTS}

The author thanks the many colleagues at the University of Calgary and
elsewhere (particularly at Osaka University and at the Technical Uni-
versity of Dresden), trainees and laboratory personnel who have con-
tributed to the studies associated with his laboratory over several years.
He also thanks the Canadian Arthritis Network, The Arthritis Society,
Canadian Institutes of Health Research, and Alberta Innovates Health
Solutions for their financial support in performing studies at the Uni-
versity of Calgary. The author also apologizes to those investigators who have made significant contributions to the fields discussed, but were not cited due to space limitations.

\section{REFERENCES}

[1] Hart, D.A., et al. (2013) The knee as an integrated, interdependent organ system: Implications for injury risk, potential for effective repair, and possible impact on return to sport. British Journal of Sports Medicine, Review, Submitted.

[2] Frank, C.B., et al. (2004) Regeneration and clinical issues in soft tissue reconstruction of the knee and shoulder. Annals of Biomedical Engineering, 32, 458-465. http://dx.doi.org/10.1023/B:ABME.0000017548.85451.b $\underline{7}$

[3] Loeser, R.F., Goldring, S.R., Scanzello, C.R. and Goldring, M.B. (2012) Osteoarthritis: A disease of the joint as an organ. Arthritis and Rheumatism, 64, 1697-1707. http://dx.doi.org/10.1002/art.34453

[4] Hart, D.A., et al. (2002) Mechanobiology: Similarities and differences between in vivo and in vitro analysis at the functional and molecular levels. Recent Research Developments in Biophysics and Biochemistry, 2, 153-177.

[5] Jadin, K.D., Wong, B.L., Bae, Kelvin, B.C., Williamson, A.K., Schumacher, B.L., Price, J.H. and Sah, R.L. (2005) Depth-varying density and organization of chondrocytes in immature and mature bovine articular cartilage assessed by 3D imaging and analysis. Journal of Histochemistry and Cytochemistry, 53, 1109-1119. http://dx.doi.org/10.1369/jhc.4A6511.2005

[6] Jadin, K.D., Bae, W.C., Schumacher, B.L. and Sah, R.L. (2007) Three-dimensional (3-D) imaging of chondrocytes in articular cartilage: Growth-associated changes in cell organization. Biomaterials, 28, 230-239.

http://dx.doi.org/10.1016/j.biomaterials.2006.08.053

[7] Hellio Le Graverand, M-P., et al. (2001) The cells of the rabbit meniscus: Their arrangement, interrelationship, morphological variations and cytoarchitecture. Journal of Anatomy, 198, 525-535.

http://dx.doi.org/10.1046/j.1469-7580.2000.19850525.x

[8] Amiel, D., et al. (1995) Intrinsic properties of ACL and MCL cells and their responses to growth factors. Medical Science and Sports Exercise, 27, 844-851. http://dx.doi.org/10.1249/00005768-199506000-00008

[9] Xie, J., Wang, C.L., Huang, D.-Y., Zhang, Y. Y., Xu, J. W., Kolesnikov, S.S., Paul Sung, K.L. and Zhao, H.C. (2013) TGF-beta1 induces the different expressions of lysyl oxidases and matrix metalloproteinases in anterior cruciate ligament and medial collateral ligament fibroblasts after mechanical injury. Journal of Biomechanics, 46, 890-898.

http://dx.doi.org/10.1016/j.jbiomech.2012.12.019

[10] Thornton, G. and Hart, D.A. (2011) The interface of mechanical loading and biological variables as they pertain to the development of tendinosis. Journal of Musculoskeletal and Neuronal Interactions, 11, 94-105.

[11] Natsu-ume, T., Majima, T., Reno, C., Shrive, N.G., Frank, C.B. and Hart, D.A. (2005) Evidence that menisci of the 
rabbit knee require mechanical loading to maintain homeostasis: Cyclic hydrostatic compression in vitro prevents derepression of catabolic genes. Journal of Orthopedic Science, 10, 396-405.

http://dx.doi.org/10.1007/s00776-005-0912-x

[12] Goulet, F., et al. (2011) Potential of tissue-engineered ligament substitutes for Ruptured ACL replacement. In: Regenerative Medicine and Tissue Engineering: From Cells to Organs, Book 2.

[13] Lee, D.H., Sonn, C.H., Han, S.-B., Oh, Y., Lee, K.-M. and Lee, S.-H. (2012) Synovial fluid CD34 (-) CD44(+) CD90(+) mesenchymal stem cell levels are associated with the severity of primary knee osteoarthritis. Osteoarthritis and Cartilage, 20, 106-109. http://dx.doi.org/10.1016/j.joca.2011.11.010

[14] Sekiya, I., Ojima, M., Suzuki, S., Yamaga, M., Horie, M., Koga, H., Tsuji, K., Miyaguchi, K., Ogishima, S., Tanaka, H. and Muneta, T. (2012) Human mesenchymal stem cells in synovial fluid increase in the knee with degenerated cartilage and osteoarthritis. Journal of Orthopedic Research, 30, 943-949. http://dx.doi.org/10.1002/jor.22029

[15] Krawetz, R.J., Wu, Y.E., Martin, L., Rattner, J.B., Matyas, J.R. and Hart, D.A. (2012) Synovial fluid progenitors expressing $\mathrm{CD} 90(+)$ from normal but not osteoarthritic joints undergo chondrogenic differentiation without micro-mass culture. PLoS One, 7, e43616. http://dx.doi.org/10.1371/journal.pone.0043616

[16] Frank, C.B. (2004) Ligament structure, physiology and function. Journal of Musculoskeletal and Neuronal Interactions, 4, 199-201.

[17] Thornton, G.M., Boorman, R.S., Shrive, N.G. and Frank, C.B. (2002) Medial collateral ligament autografts have increased creep response for at least two years and early immobilization makes this worse. Journal of Orthopedic Research, 20, 346-352.

http://dx.doi.org/10.1016/S0736-0266(01)00100-0

[18] Frank, C.B., Hart, D.A. and Shrive, N.G. (1999) Molecular biology and biomechanics of normal and healing ligaments-A review. Osteoarthritis and Cartilage, 7, 130140. http://dx.doi.org/10.1053/joca.1998.0168

[19] Achari, Y., Chin, J.W.S., Heard, B.J., Rattner, J.B., Shrive, N.G., Frank, C.B. and Hart, D.A. (2011) Molecular events surrounding collagen fibril assembly in the early healing rabbit medial collateral ligament-failure to recapitulate normal ligament development. Connective Tissue Research, 52, 301-312. http://dx.doi.org/10.3109/03008207.2010.524719

[20] Khan, W.S. and Hardingham, T.E. (2012) Cartilage tissue engineering approaches applicable in orthopaedic surgery: The past, the present, and the future. Journal of Stem Cells, 7, 97-104.

[21] Gomoll, A.H., Filardo, G., de Girolamo, L., EsprequeiraMendes, J., Marcacci, M., Rodkey, W.G., Steadman, R.J., Zaffagnini, S. and Kon, E. (2012) Surgical treatment for early osteoarthritis. Part 1: Cartilage repair procedures. Knee Surgery, Sports Traumatology and Arthroscopy, 20, 450-466. http://dx.doi.org/10.1007/s00167-011-1780-x

[22] Oldershaw, R.A. (2012) Cell sources for the regeneration of articular cartilage: The past, the horizon and the future. International Journal of Experimental Pathology, 93, 389-400.

[23] Bentley, G., Bhamra, J.S., Gikas, P.D., Skinner, J.A., Carrington, R. and Briggs, T.W. (2013) Repair of osteochondral defects in joints-how to achieve success. Injury, 44, S3-S10. http://dx.doi.org/10.1016/S0020-1383(13)70003-2

[24] Haddad, B., Pakravan, A.H., Konan, S., Adesida, A. and Khan, W. (2013) A systematic review of tissue engineered meniscus: Cell-based preclinical models. Current Stem Cell Research and Therapeutics, 8, 222-231. http://dx.doi.org/10.2174/1574888X11308030007

[25] Trinh, T.Q., Harris, J.D., Siston, R.A. and Flanigan, D.C. (2013) Improved outcomes with combined autologous chondrocyte implantation and patellofemoral osteotomy versus isolated autologous chondrocyte implantation. Arthroscopy, 29, 566-574. http://dx.doi.org/10.1016/j.arthro.2012.10.008

[26] Nakamura, N., et al. (2000) Decorin antisense gene therapy improves functional healing of early rabbit ligament scar with enhanced collagen fibrillogenesis in vivo. Journal of Orthopedic Research, 18, 517-523. http://dx.doi.org/10.1002/jor.1100180402

[27] Nakamura, N., Hart, D.A., Frank, C.B., Marchuk, L.L., Shrive, N.G., Ota, N., Taira, K., Yoshikawa, H. and Kaneda, Y. (2001) Efficient transfer of intact oligonucleotides into the nucleus of ligament scar fibroblasts by HVJ-cationic liposomes is correlated with effective antisense gene inhibition. Journal of Biochemistry, 129, 755-759.

http://dx.doi.org/10.1093/oxfordjournals.jbchem.a002916

[28] Hart, D.A., et al. (2000) Complexity of determining cause and effect in vivo after antisense gene therapy. Clinical Orthopedics and Related Research, 379, S242-251. http://dx.doi.org/10.1097/00003086-200010001-00032

[29] Hart, D.A., et al. (2000) Functional improvement in ligament scar tissue following anti-sense gene therapy: A model system for in vivo engineering of connective tissues. Gene Therapy and Molecular Biology, 4, 85-90.

[30] Sanchez, M., et al. (2009) Platelet-rich therapies in the treatment of orthopaedic sport injuries. Sports Medicine, 39, 345-354.

[31] Tschon, M., Fini, M., Giardino, R., Filardo, G., Dallari, D., Torricelli, P., Martini, L., Giavaresi, G., Kon, E., Maltarello, M.C., Nicolini, A. and Carpi, A. (2011) Lights and shadows concerning platelet products for musculoskeletal regeneration. Frontiers of Bioscience (Elite Edition), 3, 96-107. http://dx.doi.org/10.2741/e224

[32] Stanco, D., Vigano, M., Croiset, S.J. and De Girolamo, L. (2012) Applications and limits of platelet-rich plasma in sports related injuries. Journal of Biological Regulators and Homeostatic Agents, 26, 53S-61S.

[33] Andia, I., Sánchez, M. and Maffulli, N. (2012) Joint pathology and platelet-rich plasma therapies. Expert Opinion on Biological Therapy, 12, 7-22. http://dx.doi.org/10.1517/14712598.2012.632765

[34] Smyth, N.A., Murawski, C.D., Fortier, L.A., Cole, B.J. and Kennedy, J.G. (2013) Platelet-rich plasma in the pa- 
thologic processes of cartilage: A review of basic science evidence. Arthroscopy, 29, 1399-1409. http://dx.doi.org/10.1016/j.arthro.2013.03.004

[35] Hildebrand, K.A., et al. (2002) Exogenous TGF-beta1 alone does not improve early rabbit MCL healing in vivo. Canadian Journal of Surgery, 45, 330-336.

[36] Mammoto, T., Seerattan, R.A., Paulson, K.D., Leonard, C.A., Bray, R.C. and Salo, P.T. (2008) Nerve growth factor improves ligament healing. Journal of Orthopedic Research, 26, 957-964. http://dx.doi.org/10.1002/jor.20615

[37] Ackermann, P., Salo, P. and Hart, D.A. (2009) Neuronal influences on tendon healing. Frontiers in Bioscience, 14, 5165-5187. http://dx.doi.org/10.2741/3593

[38] Scharstuhl, A., et al. (2002) Inhibition of endogenous TGF-beta during experimental osteoarthritis prevents osteophyte formation and impairs cartilage repair. Journal of Immunology, 169, 507-514.

[39] Alan, C., Kocoglu, H., Altıntas, R., Alıc1, B. and Ersay, A.R. (2011) Protective effect of decorin on acute ischaemia-reperfusion injury in the rat kidney. Archives of Medical Science, 7, 211-216. http://dx.doi.org/10.5114/aoms.2011.22069

[40] Kolb, M., Margetts, P.J., Galt, T., Sime, P.J., Xing, Z., Schmidt, M. and Gauldie, J. (2001) Transient trangene expression of decorin in the lung reduces the fibrotic response to bleomycin. American Journal of Respiratory and Critical Care Medicine, 163, 770-777. http://dx.doi.org/10.1164/ajrccm.163.3.2006084

[41] Goyal, D., Keyhani, S., Lee, E.H. and Hui, J.H.P. (2013) Evidence-based status of microfracture technique: A systematic review of level I and II studies. Arthroscopy, 29, 1579-1588. http://dx.doi.org/10.1016/j.arthro.2013.05.027

[42] Roelofs, A.J., Rocke, J.P.J. and De Bari, C. (2013) Cellbased approaches to joint surface repair: A research perspective. Osteoarthritis and Cartilage, 21, 892-900. http://dx.doi.org/10.1016/j.joca.2013.04.008

[43] Gudas, R., Gudaitè, A., Pocius, A., Gudienè, A., Čekanauskas, E., Monastyreckienė, E. and Basevičius, A. (2012) Ten-year follow-up of a prospective, randomized clinical study of mosaic osteochondral autologous transplantation versus microfracture for the treatment of osteochondral defects in the knee joint of athletes. American Journal of Sports Medicine, 40, 2499-2508.

http://dx.doi.org/10.1177/0363546512458763

[44] Gimble, J.M., E., Bunnell, B.A. and Guilak, F. (2012) Human adipose-derived cells: An update on the transition to clinical translation. Regenerative Medicine, 7, 225-235. http://dx.doi.org/10.2217/rme.11.119

[45] Alegre-Aguaron, E., Desportes, P., García-Álvarez, F., Castiella, T., Larrad, L. and Martínez-Lorenzo, M.J. (2012) Differences in surface marker expression and chondrogenic potential among various tissue-derived mesenchymal cells from elderly patients with osteoarthritis. Cells, Tissues and Organs, 196, 231-240.

[46] Dhanasekaran, M., Indumathi, S., Kanmani, A., Poojitha, R., Revathy, K.M., Rajkumar, J.S. and Sudarsanam, D. (2012) Surface antigenic profiling of stem cells from hu- man omentum fat in comparison with subcutaneous fat and bone marrow. Cytotechnology, 64, 497-509.

http://dx.doi.org/10.1007/s10616-012-9427-4

[47] Ando, W., Heard, B.J., Chung, M., Nakamura, N., Frank, C.B. and Hart, D.A. (2012) Ovine synovial membranederived mesenchymal progenitor cells retain the phenotype of the original tissue that was exposed to in-vivo inflammation: Evidence for a suppressed chondrogenic differentiation potential of the cells. Inflammation Research, 61, 599-608. http://dx.doi.org/10.1007/s00011-012-0450-x

[48] Ando, W., et al. (2014) Clonal analysis of synovial fluid stem cells to characterize and identify stable MSC/MPC phenotypes in a porcine model: A cell source with enhanced commitment to the chondrogenic lineage. Cytotherapy, in press.

[49] Manuelpillai, U., Moodley, Y., Borlongan, C.V. and Parolini, O. (2011) Amniotic membrane and amniotic cells: Potential therapeutic tools to combat tissue inflammation and fibrosis? Placenta, 32, S320-S325.

http://dx.doi.org/10.1016/j.placenta.2011.04.010

[50] Longo, U.G., Loppini, M., Berton, A., La Verde, L., Khan, W.S. and Denaro, V. (2012) Stem cells from umbilical cord and placenta for musculoskeletal tissue engineering. Current Stem Cell Research and Therapy, 7, 272-281. http://dx.doi.org/10.2174/157488812800793054

[51] Bulman, S.E., Barron, V., Coleman, C.M. and Barry, F. (2013) Enhancing the mesenchymal stem cell therapeutic response: Cell localization and support for cartilage repair. Tissue Engineering (Part B) Reviews, 19, 58-68.

[52] Izuta, Y., Ochi, M., Adachi, N., Deie, M., Yamasaki, T. and Shinomiya, R. (2005) Meniscal repair using bone marrow-derived mesenchymal stem cells: Experimental study using green fluorescent protein transgenic rats. Knee, 12, 217-223. http://dx.doi.org/10.1016/j.knee.2001.06.001

[53] Heard, B.J., Fritzler, M.J., Wiley, J.P., McAllister, J., Martin, L., El-Gabalawy, H., Hart, D.A., Frank, C.B. and Krawetz, R. (2013) Intraarticular and systemic inflammatory profiles may identify patients with osteoarthritis. Journal of Rheumatology, 40, 1379-1387. http://dx.doi.org/10.3899/jrheum.121204

[54] Harris, Q., Seto, J., O’Brien, K., Lee, P.S., Kondo, C., Heard, B.J., Hart, D.A. and Krawetz, R.J. (2013) Monocyte chemotactic protein-1 inhibits chondrogenesis of synovial mesenchymal progenitor cells: An in vitro study. Stem Cells, 31, 2253-2265. http://dx.doi.org/10.1002/stem.1477

[55] Hart, D.A., Kydd, A.S., Frank, C.B. and Hildebrand, K.A. (2004) Tissue repair in Rheumatoid Arthritis: Challenges and opportunities in the face of a systemic inflammatory disease. Best Practices and Research in Clinical Rheumatology, 18, 187-202. http://dx.doi.org/10.1016/j.berh.2004.02.007

[56] Abumaree, M., Al Jumah, M., Pace, R.A. and Kalionis, B. (2012) Immunosuppressive properties of mesenchymal stem cells. Stem Cell Reviews and Reports, 8, 375-392. http://dx.doi.org/10.1007/s12015-011-9312-0

[57] Soleymaninejadian, E., Pramanik, K. and Samadian, E. 
(2012) Immunomodulatory properties of mesenchymal stem cells: Cytokines and factors. American Journal of Reproductive Immunology, 67, 1-8. http://dx.doi.org/10.1111/j.1600-0897.2011.01069.x

[58] Koh, Y.G., Jo, S.B., Kwon, O.R., Suh, D.S., Lee, S.W., Park, S.H. and Choi, Y.J. (2013) Mesenchymal stem cell injections improve symptoms of knee osteoarthritis. Arthroscopy, 29, 748-755. http://dx.doi.org/10.1016/j.arthro.2012.11.017

[59] Orozco, L., Munar, A., Soler, R., Alberca, M., Soler, F., Huguet, M., Sentís, J., Sánchez, A. and García-Sancho, J. (2013) Treatment of knee osteoarthritis with autologous mescenchymal stem cells: A pilot study. Transplantation, 95, 1535-1541. http://dx.doi.org/10.1097/TP.0b013e318291a2da

[60] Hauser, R.A. and Orolfsky, A. (2013) Regenerative injection therapy with whole bone marrow aspirate for degenerative joint disease: A case series. Clinical and Medical Insights in Arthritis and Musculokeletal Disorders, 6, 65-72.

[61] Goulet, F., Rancourt, D., Cloutier, R., Tremblay, P., Belzil, A.M., Lamontagne, J., Bouchard, M., Tremblay, J., Stevens, L.M., Labrosse, J., Langelier, E. and McKee, M.D. (2004) Torn ACL: A new bioengineered substitute brought from the laboratory to the knee joint. Applied Bionics and Biomechanics, 1, 115-121. http://dx.doi.org/10.1533/abib.2004.1.2.115

[62] Frank, C.B. and Hart, D.A. (2004) Clinical application of tissue engineered tendon and ligament. In: Sandell, L. and Grodzinsky, A.J., Eds., Tissue Engineering in Musculoskeletal Clinical Practice, AAOS, Rosemont, 2410256.

[63] Hart, D.A., Shrive, N.G. and Goulet, F. (2005) Tissue engineering of ACL replacements. Sports Medicine and Arthroscopy Reviews, 13, 170-176. http://dx.doi.org/10.1097/01.jsa.0000173242.15191.70

[64] Ando, W., Tateishi, K., Hart, D.A., Katakai, D., Tanaka, Y., Nakata, K., Hashimoto, J., Fujie, H., Shino, K., Yoshikawa, H. and Nakamura, N. (2007) Cartilage repair using an in vitro generated scaffold-free tissue-engineered construct derived from porcine synovial mesenchymal stem cells. Biomaterials, 28, 5462-5470. http://dx.doi.org/10.1016/j.biomaterials.2007.08.030

[65] Ando, W., et al. (2012) Detection of abnormalities in the superficial zone of cartilage repaired using a tissue engineered construct derived from synovial stem cells. European Cells \& Materials, 24, 292-307.

[66] Matsusaki, M., Kadowaki, K., Tateishi, K., Higuchi, C., Ando, W., Hart, D.A., Tanaka, Y., Take, Y., Akashi, M., Yoshikawa, H. and Nakamura, N. (2009) Scaffold-free tissue-engineered construct-hydroxyapatite composites generated by an alternate soaking process: Potential for repair of bone defects. Tissue Engineering, Part A, 15, 55-63. http://dx.doi.org/10.1089/ten.tea.2007.0424

[67] Moriguchi, Y., Tateishi, K., Ando, W., Shimomura, K., Yonetani, Y., Tanaka, Y., Kita, K., Hart, D.A., Gobbi, A., Shino, K., Yoshikawa, H. and Nakamura, N. (2013) Repair of meniscal lesions using a scaffold-free tissue-engineered construct derived from allogenic synovial MSCs in a miniature swine model. Biomaterials, 34, 2185-2193. http://dx.doi.org/10.1016/j.biomaterials.2012.11.039

[68] Shimomura, K., Ando, W., Tateishi, K., Nansai, R., Fujie, H., Hart, D.A., Kohda, H., Kita, K., Kanamoto, T., Mae, T., Nakata, K., Shino, K., Yoshikawa, H. and Nakamura, N. (2010) The influence of skeletal maturity on allogenic synovial mesenchymal stem cell-based repair of cartilage in a large animal model. Biomaterials, 31, 8004-8011. http://dx.doi.org/10.1016/j.biomaterials.2010.07.017

[69] Ando, W., Tateishi, K., Katakai, D., Hart, D.A., Higuchi, C., Nakata, K., Hashimoto, J., Fujie, H., Shino, K., Yoshikawa, H. and Nakamura, N. (2008) In vitro generation of a scaffold-free tissue-engineered construct (TEC) derived from human synovial mesenchymal stem cells: Biological and mechanical properties, and further chondrogenic potential. Tissue Engineering, Part A, 14, 20412049. http://dx.doi.org/10.1089/ten.tea.2008.0015 